\title{
Antimicrobial Potential of Calcium Hydroxide Chlorhexidine, Octenidol, Endoseptone and Combination of Calcium Hydroxide and Chlorhexidine against Enterococcus faecalis as Intracanal Medicament
}

\author{
Aakriti $^{1}{ }^{(D)}$, Dildeep Bali ${ }^{1}$, Preeti Sharma ${ }^{2 *}$ (D), Vijaya Dhar Bhatt ${ }^{1}$ (D) Prashant $^{2}$ \\ Bhasin $^{1}$, Era Arora ${ }^{1}$ (D), Suhrab Singh ${ }^{1}$ and Pradeep Kumar ${ }^{2}$ \\ ${ }^{1}$ Department of Conservative Dentistry and Endodontics, Santosh Medical and Dental College, Ghaziabad - 201009, \\ India. ${ }^{2}$ Department of Biochemistry, Santosh Medical and Dental College, Ghaziabad - 201009, India.
}

\begin{abstract}
The complete microfloral debriment of the root canal is possible only through successful endodontic treatment. Due to complexicity constraints of root canal system complete microfloral removal by simply mechanical instruments is not sufficient. Therefore we aim to evaluate the antimicrobial efficacy of five different intracanal medicaments such as calcium hydroxide, chlorhexidiene, octenidol, endosepton and calcium hydroxide and chlorhexidine against Enterococcus faecalis. The Antibacterial activity of aforesaid medicaments was done against Enterococcus feacalis using agar disk diffusion method, over a period of $24 \mathrm{hrs}$ and $72 \mathrm{hrs}$. The samples were divided into 6 groups. The zone of inhibition was measured after 24 and $72 \mathrm{hrs}$ and were recorded in millimeters and compared with respect to control. There was a significant difference in the mean zone of inhibition at 24 and $72 \mathrm{hrs}$ between calcium hydroxide, endoseptone, octenidol, calcium hydroxide and chlorohexidine combination, chlorohexidine and control group. Chlorohexidine was found to have maximum inhibitory efficacy followed by calcium hydroxide and chlorohexidine combination. Within the limitations of this study it may be concluded that Chlorhexidine can be used as an efficient intracanal medicament.

Keywords: Intracanal medicament, Octenidol, Endoseptone, Chlorhexidine.
\end{abstract}

*Correspondence: prcdri2003@yahoo.co.in

(Received: 30 June 2019; accepted: 08 August 2019)

Citation: Aakriti, Dildeep Bali, Preeti Sharma, Vijaya Dhar Bhatt, Prashant Bhasin, Era Arora, Suhrab Singh and Pradeep Kumar, Antimicrobial Potential of Calcium Hydroxide Chlorhexidine, Octenidol, Endoseptone and Combination of Calcium Hydroxide and Chlorhexidine against Enterococcus faecalis as Intracanal Medicament, J Pure Appl Microbiol., 2019; 13(3): 1725-1735. https:// doi.org/10.22207/JPAM.13.3.47

(C) The Author(s) 2019. Open Access. This article is distributed under the terms of the Creative Commons Attribution 4.0 International License which permits unrestricted use, sharing, distribution, and reproduction in any medium, provided you give appropriate credit to the original author(s) and the source, provide a link to the Creative Commons license, and indicate if changes were made. 


\section{INTRODUCTION}

Complete debridement and reduction of bacterial infection from root canal space seems to be necessary for long term success of endodontic treatment ${ }^{1,2}$. However, the complex anatomy of the root canal system sometimes hinders the penetration of irrigants / medicaments which are necessary for eradication of infected tissues and micro-organisms ${ }^{3}$ resulting in non / partial elimination of resistant bacteria within root canal systems. Various bacteria found in root canals are Enterococcus faecalis, Streptococcus mutans, Streptococcus sanguis and Staphylococcus aureus ${ }^{4}$.

Enterococcus faecalis is a troublemaker among many causative agents of failed root canal treatment ${ }^{5}$. It has been found in $38 \%$ of failed root canal system. However, according to Miller and Wilkins study, Enterococcus faecalis ranges from $24-77 \%$ in tooth with failed endodontic treatment ${ }^{6}$. Its high alkalinity tolerance enables it to tolerate rough environmental changes ${ }^{7}$. Despite the use of different intracanal medicaments few bacteria are capable of surviving in the root canal dentin ${ }^{8}$ which is the major reason behind endodontic treatment failure ${ }^{9}$.

Different intracanal medicaments have been used over the time like formocresol, glutaraldehyde, calcium hydroxide, chlorhexidine gel, corticosteroids, and certain antibiotics ${ }^{10}$. Among the numerous properties accounted for in an ideal intracanal medicament, stability, biocompatibility, and antibacterial action are the most important factors to prevent multiplication of certain microorganisms between intraappointment visits $^{11-12}$. Therefore, the search for potent intracanal medication with wide antimicrobial spectrum and low cytotoxicity continues.

The purpose of this study was to investigate the efficacy of five different intracanal medicaments against Enterococcus faecalis. These medicaments are calcium hydroxide, endoseptone, octenidol, calcium hydroxide and chlorohexidine combination, chlorohexidine. Many studies have been carried out on the antimicrobial efficacy of calcium hydroxide and Chlorhexidine ${ }^{13}$ in the past but none comparing recently introduced Octenidol with the standard calcium hydroxide ${ }^{14}$. Hence, this study was undertaken to compare and evaluate the antimicrobial potency of Octenidol against
Chlorhexidine, Endoseptone and standard calcium hydroxide.

Two parameters were selected to be evaluated in this study:

(1) Zone of inhibition: that is the area (measured in millimetres) around the wafer where the bacteria has not grown enough to be visible, which tells us how effective the intracanal medicament is at stopping the growth of bacterium ${ }^{15}$.

(2) Colony forming units: that is used to estimate the number of viable bacterium in given samples ${ }^{16}$.

\section{MATERIAL AND METHODS}

A single stranded strain of Enterococcus faecalis ATCC 29212 was used for this study. The inoculation of bacteria was done by transferring the bacteria to the liquid medium that is Trypticase soy broth. Transferring of bacteria was done by heating sterile inoculation loops until red hot after which the bacteria was picked up from the Enterococcus faecalis strains and was carried to the test tube containing Trypticase soy broth. The mouth of the test tube was run through the flame before inserting the loop carrying bacteria in order to avoid contaminants at the entrance of the test tube. The loops was then rubbed along the wall of the test tube by holding the tube at 45 degrees. The tip of the test tube was again run through the flame and was capped. This test tube was incubated for 12 hours at 37 degrees. The turbidity was seen in the test tube after 12 hours which indicated the growth of active bacterium. For the confirmation of single stranded strains of Enterococci, a slide was prepared and was gram stained. This procedure involved the application of primary stain crystal violet to a heat fixed smear of bacterial culture followed by addition of trapping agent grams iodine which is preceded by rapid decolourization with alcohol and finally basic fuchsin was used for counter staining. Oil immersion microscopic examination at lens power 100x was done which confirmed Enterococci by their purple colour with rounded appearances, either in chains or bunch. 15 trypticase soy agar plates were swabbed by Enterococcus faecalis using sterile cotton swabs by dipping the swabs into the test tube containing broth and transferring them to each trypticase soy agar plates by moving the swabs on each plate in a "zig -zag"motion as quickly as possible to avoid any air contamination. 
The test agents were measured at 5 microlitres and were transferred to these punched wells using a sterile micropipette.

These plates were labelled on the back of the agar plates and was incubated for 24 hours at 37 degrees.

The test agents were as follows :

Group 1 : Positive Control

Group 2 : Calcium hydroxide -1.5 gm of powder in $1 \mathrm{ml}$ of sterile saline.

Group 3 : 2\% Chlorhexidine

Group 4 : Endoseptone

Group 5 : Octenidol

Group 6 : Combination of calcium hydroxide and Chlorhexidine $(1: 1)$

The entire experiment was done under sterilized condition.

After 24 hours and 72 hours the zone of inhibition was measured of each test agent in millimetres by holding a ruler on the back of the agar plates and the readings were noted.
The enterococci were suspended in a solution of trypticase soy broth. 100 microlitre of this was pipetted out and poured onto brainheart-infusion agar. Streaking was done using a sterile metal loop in order to evenly spread the suspension all through the agar plate. The plates were then incubated for 24 hours and further using a digital colony counter, the colony forming units (CFU) were enumerated. The mean CFU/mg and standard deviation values were calculated for calcium hydroxide and Chlorhexidine groups. Statistical significance was established at $p<0.01$.

\section{RESULTS}

The mean Zone of inhibition at 24 hours was compared between Calcium hydroxide, Endoseptone, Octenidol, Calcium hydroxide and Chlorhexidine combination, Chlorhexidine and Control groups using the One-way ANOVA test. There was a significant difference in mean Zone of inhibition at 24 hours between Calcium hydroxide,

Table 1. The mean zone of inhibition at 24 hours

\begin{tabular}{lccccc}
\hline & \multicolumn{4}{c}{ Zone of inhibition at 24 hours } & \multirow{2}{*}{ Number } \\
& Mean & Std. Deviation & F-value & p-value \\
\hline Calcium hydroxide & 15 & 0.00 & 0.00 & 613.780 & $<0.001^{*}$ \\
Endoseptone & 15 & 12.60 & 1.97 & \\
Octenidol & 15 & 15.00 & 2.33 & \\
Calcium hydroxide and & 15 & 18.00 & 1.25 & \\
Chlorhexidine combination & & & & \\
CHLORHEXIDINE & 15 & 22.00 & 1.32 & \\
Control group & 15 & 0.00 & 0.00 & \\
& & & &
\end{tabular}

One-way ANOVA test* Significant difference

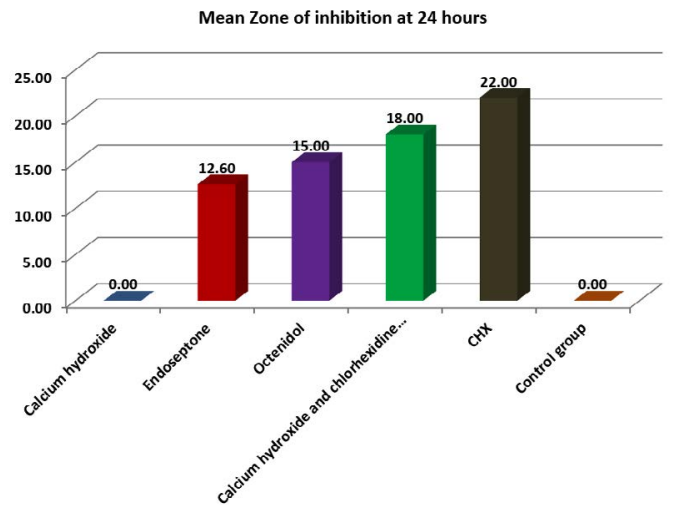

Fig. 1. Showing comparative account of mean zone of inhibition at 24 hours

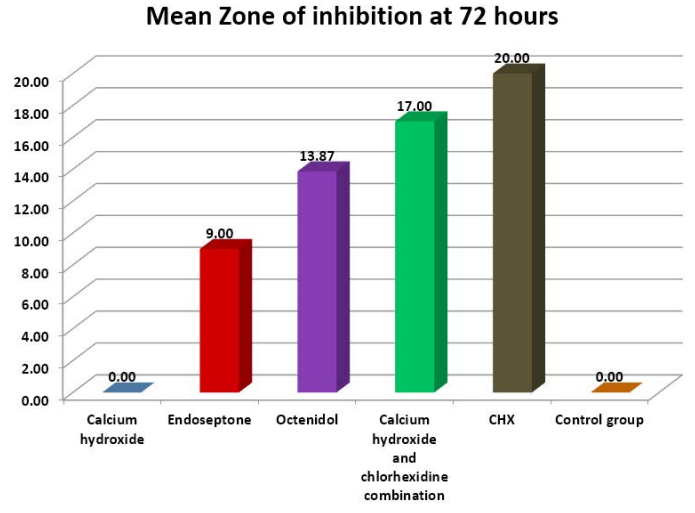

Fig. 2. Showing zone of inhibition at 72 hours 
Endoseptone, Octenidol, Calcium hydroxide and Chlorhexidine combination, Chlorhexidine and Control groups.

The inter-group comparison of mean Zone of inhibition at 24 hours was done using the Post-hoc bonferroni test. The mean Zone of inhibition at 24 hours was significantly more among Chlorhexidine in comparison to other groups, Calcium hydroxide and Chlorhexidine combination in comparison to Calcium hydroxide, Endoseptone, Octenidol and control groups, Octenidol comparison to Calcium hydroxide, Endoseptone and control groups and Endoseptone in comparison to Calcium hydroxide and control groups.

The mean Zone of inhibition at 72 hours was compared between Calcium hydroxide, Endoseptone, Octenidol, Calcium hydroxide and Chlorhexidine combination, Chlorhexidine and Control groups using the One-way ANOVA test. There was a significant difference in mean Zone of inhibition at 72 hours between Calcium hydroxide, Endoseptone, Octenidol, Calcium hydroxide and
Chlorhexidine combination, Chlorhexidine and Control groups.

The inter-group comparison of mean Zone of inhibition at 72 hours was done using the Post-hoc bonferroni test. The mean Zone of inhibition at 72 hours was significantly more among Chlorhexidine in comparison to other groups, Calcium hydroxide and Chlorhexidine combination in comparison to Calcium hydroxide, Endoseptone, Octenidol and control groups, Octenidol in comparison to Calcium hydroxide, Endoseptone and control groups and Endoseptone in comparison to Calcium hydroxide and control groups.

The mean CFU at day 1 was compared between Calcium hydroxide, Endoseptone, Octenidol, Calcium hydroxide and Chlorhexidine combination, Chlorhexidine and Control groups using the One-way ANOVA test. There was a significant difference in mean CFU at day 1 between Calcium hydroxide, Endoseptone, Octenidol, Calcium hydroxide and Chlorhexidine combination, Chlorhexidine and Control groups.

Table 2. Difference of zone of inhibition of various medicaments

\begin{tabular}{|c|c|c|c|}
\hline & Zone of inhibition at 24 hours & $\begin{array}{l}\text { Mean } \\
\text { Difference }\end{array}$ & $\mathrm{p}$-value \\
\hline Calcium hydroxide & Endoseptone & -12.60 & $<0.001^{*}$ \\
\hline Calcium hydroxide & Octenidol & -15.00 & $<0.001^{*}$ \\
\hline Calcium hydroxide & $\begin{array}{l}\text { Calcium hydroxide and } \\
\text { Chlorhexidine combination }\end{array}$ & -18.00 & $<0.001^{*}$ \\
\hline Calcium hydroxide & CHLORHEXIDINE & -22.00 & $<0.001^{*}$ \\
\hline Calcium hydroxide & Control group & 0.00 & 1.000 \\
\hline Endoseptone & Octenidol & -2.40 & $<0.001^{*}$ \\
\hline Endoseptone & $\begin{array}{l}\text { Calcium hydroxide and } \\
\text { Chlorhexidine combination }\end{array}$ & -5.40 & $<0.001^{*}$ \\
\hline Endoseptone & CHLORHEXIDINE & -9.40 & $<0.001^{*}$ \\
\hline Endoseptone & Control group & 12.60 & $<0.001^{*}$ \\
\hline Octenidol & $\begin{array}{l}\text { Calcium hydroxide and } \\
\text { Chlorhexidine combination }\end{array}$ & -3.00 & $<0.001^{*}$ \\
\hline Octenidol & CHLORHEXIDINE & -7.00 & $<0.001^{*}$ \\
\hline Octenidol & Control group & 15.00 & $<0.001^{*}$ \\
\hline $\begin{array}{l}\text { Calcium hydroxide and } \\
\text { Chlorhexidine combination }\end{array}$ & CHLORHEXIDINE & -4.00 & $<0.001^{*}$ \\
\hline $\begin{array}{l}\text { Calcium hydroxide and } \\
\text { Chlorhexidine combination }\end{array}$ & Control group & 18.00 & $<0.001 *$ \\
\hline CHLORHEXIDINE & Control group & 22.00 & $<0.001^{*}$ \\
\hline
\end{tabular}

Post-hoc bonferroni test* Significant difference 
The inter-group comparison of mean CFU at day 1 was done using the Post-hoc bonferroni test. The mean CFU at day 1 was significantly more among Chlorhexidine in comparison to Calcium hydroxide, Endoseptone, Octenidol and control groups, Calcium hydroxide and Chlorhexidine combination in comparison to Calcium hydroxide, Endoseptone, Octenidol and control groups, Octenidol in comparison to Calcium hydroxide, Endoseptone and control groups and Endoseptone in comparison to Calcium hydroxide and control groups.

The mean CFU at day 3 was compared between Calcium hydroxide, Endoseptone, Octenidol, Calcium hydroxide and Chlorhexidine combination, Chlorhexidine and Control groups using the One-way ANOVA test. There was a significant difference in mean CFU at day 3 between Calcium hydroxide, Endoseptone, Octenidol, Calcium hydroxide and Chlorhexidine combination, Chlorhexidine and Control groups.
The inter-group comparison of mean CFU at day 3 was done using the Post-hoc bonferroni test ${ }^{17}$. The mean CFU at day 3 was significantly more among Chlorhexidine in comparison to Calcium hydroxide, Endoseptone, Octenidol and control groups, Calcium hydroxide and Chlorhexidine combination in comparison to Calcium hydroxide, Endoseptone, Octenidol and control groups, Octenidol in comparison to Calcium hydroxide, Endoseptone and control groups and Endoseptone in comparison to Calcium hydroxide and control groups.

The mean CFU at day 5 was compared between Calcium hydroxide, Endoseptone, Octenidol, Calcium hydroxide and Chlorhexidine combination, Chlorhexidine and Control groups using the One-way ANOVA test. There was a significant difference in mean CFU at day 5 between Calcium hydroxide, Endoseptone, Octenidol, Calcium hydroxide and Chlorhexidine combination, CHLORHEXIDINE and Control groups.

Table 3. Zone of inhibition at 72 hours

\begin{tabular}{|c|c|c|c|c|c|}
\hline \multicolumn{6}{|c|}{ Zone of inhibition at 72 hours } \\
\hline & Number & Mean & Std. Deviation & F-value & $p$-value \\
\hline Calcium hydroxide & 15 & 0.00 & 0.00 & 834.293 & $<0.001^{*}$ \\
\hline Endoseptone & 15 & 9.00 & 1.22 & & \\
\hline Octenidol & 15 & 13.87 & 2.02 & & \\
\hline $\begin{array}{l}\text { Calcium hydroxide and } \\
\text { Chlorhexidine combination }\end{array}$ & 15 & 17.00 & 1.07 & & \\
\hline CHLORHEXIDINE & 15 & 20.00 & 1.07 & & \\
\hline Control group & 15 & 0.00 & 0.00 & & \\
\hline
\end{tabular}

One-way ANOVA test* Significant difference

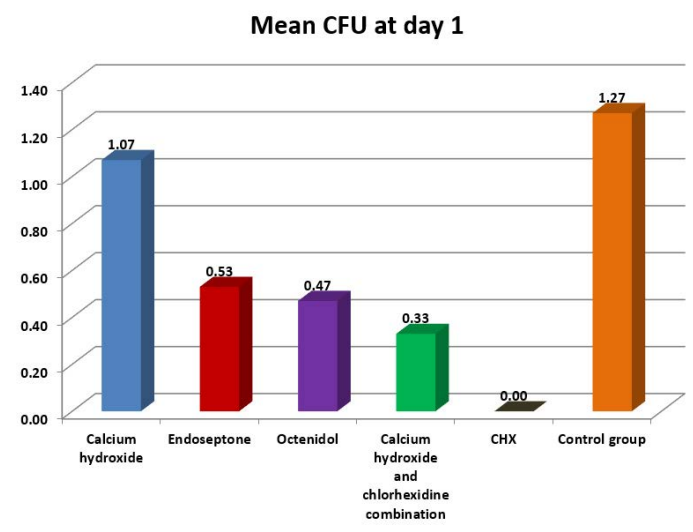

Fig. 3. CFU at day 1 by various medicament

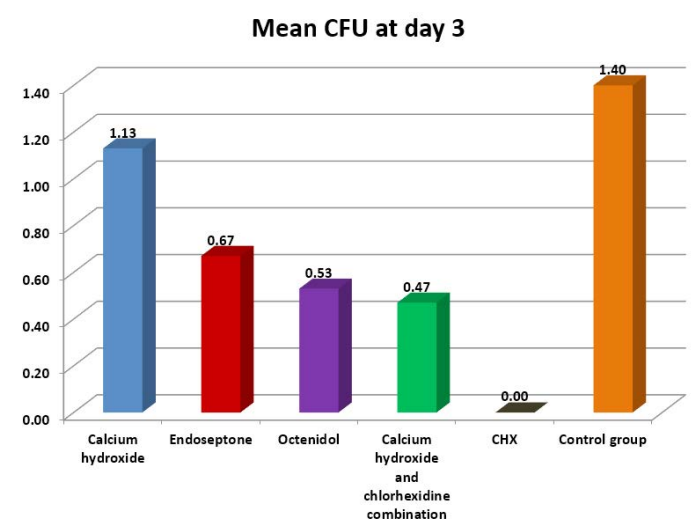

Fig. 4. CFU at day 3 by various medicament 
Table 4. Difference of zone of inhibition of various medicament at 72 hours

\begin{tabular}{|c|c|c|c|}
\hline & \multirow[t]{2}{*}{ Zone of inhibition at 72 hours } & \multirow[b]{2}{*}{ Mean Difference } & \multirow[b]{2}{*}{$p$-value } \\
\hline & & & \\
\hline Calcium hydroxide & Endoseptone & -9.00 & $<0.001 *$ \\
\hline Calcium hydroxide & Octenidol & -13.87 & $<0.001^{*}$ \\
\hline Calcium hydroxide & $\begin{array}{l}\text { Calcium hydroxide and } \\
\text { Chlorhexidine combination }\end{array}$ & -17.00 & $<0.001 *$ \\
\hline Calcium hydroxide & CHLORHEXIDINE & -20.00 & $<0.001^{*}$ \\
\hline Calcium hydroxide & Control group & 0.00 & 1.000 \\
\hline Endoseptone & Octenidol & -4.87 & $<0.001 *$ \\
\hline Endoseptone & $\begin{array}{l}\text { Calcium hydroxide and } \\
\text { Chlorhexidine combination }\end{array}$ & -8.00 & $<0.001 *$ \\
\hline Endoseptone & CHLORHEXIDINE & -11.00 & $<0.001^{*}$ \\
\hline Endoseptone & Control group & 9.00 & $<0.001 *$ \\
\hline Octenidol & $\begin{array}{l}\text { Calcium hydroxide and } \\
\text { Chlorhexidine combination }\end{array}$ & -3.13 & $<0.001^{*}$ \\
\hline Octenidol & CHLORHEXIDINE & -6.13 & $<0.001^{*}$ \\
\hline Octenidol & Control group & 13.87 & $<0.001 *$ \\
\hline $\begin{array}{l}\text { Calcium hydroxide and } \\
\text { Chlorhexidine combination }\end{array}$ & CHLORHEXIDINE & -3.00 & $<0.001 *$ \\
\hline $\begin{array}{l}\text { Calcium hydroxide and } \\
\text { Chlorhexidine combination }\end{array}$ & Control group & 17.00 & $<0.001^{*}$ \\
\hline CHLORHEXIDINE & Control group & 20.00 & $<0.001 *$ \\
\hline
\end{tabular}

Post-hoc bonferroni test* Significant difference

Table 5. CFU at day 1 by various medicaments

\begin{tabular}{lccccc}
\hline & Number & $\begin{array}{c}\text { CFU at day } 1 \\
\text { Mean }\end{array}$ & Std. Deviation & F-value & p-value \\
\hline Calcium hydroxide & 15 & 1.07 & 0.26 & 19.155 & $<0.001^{*}$ \\
Endoseptone & 15 & 0.53 & 0.52 & & \\
Octenidol & 15 & 0.47 & 0.52 & & \\
Calcium hydroxide and & 15 & 0.33 & 0.49 & \\
Chlorhexidine combination & & & & \\
CHLORHEXIDINE & 15 & 0.00 & 0.00 & \\
Control group & 15 & 1.27 & 0.46 & \\
\hline
\end{tabular}

One-way ANOVA test* Significant difference

The inter-group comparison of mean CFU at day 5 was done using the Post-hoc bonferroni test. The mean CFU at day 5 was significantly more among Chlorhexidine in comparison to Calcium hydroxide, Endoseptone, Octenidol and control groups, Calcium hydroxide and Chlorhexidine combination in comparison to Calcium hydroxide, Endoseptone, Octenidol and control groups, Octenidol in comparison to Calcium hydroxide, Endoseptone and control groups and Endoseptone in comparison to Calcium hydroxide and control groups.

\section{DISCUSSION}

Antimicrobial property of calcium hydroxide providing alkalinity to persisting environment is through production of hydroxyl ions which is a difficult condition for survival of microorganisms. However calcium hydroxide has not been found sufficiently effective against all 
Table 6. Difference of CFU at day 1, between various medicaments

\begin{tabular}{|c|c|c|c|}
\hline \multicolumn{4}{|c|}{ CFU at day 1} \\
\hline & & Mean Difference & $p$-value \\
\hline Calcium hydroxide & Endoseptone & 0.53 & $0.011 *$ \\
\hline Calcium hydroxide & Octenidol & 0.60 & $0.003^{*}$ \\
\hline Calcium hydroxide & $\begin{array}{l}\text { Calcium hydroxide and } \\
\text { Chlorhexidine combination }\end{array}$ & 0.73 & $<0.001^{*}$ \\
\hline Calcium hydroxide & CHLORHEXIDINE & 1.07 & $<0.001^{*}$ \\
\hline Calcium hydroxide & Control group & -0.20 & 1.000 \\
\hline Endoseptone & Octenidol & 0.07 & 1.000 \\
\hline Endoseptone & $\begin{array}{l}\text { Calcium hydroxide and } \\
\text { Chlorhexidine combination }\end{array}$ & 0.20 & 1.000 \\
\hline Endoseptone & CHLORHEXIDINE & 0.53 & $0.011^{*}$ \\
\hline Endoseptone & Control group & -0.73 & $<0.001^{*}$ \\
\hline Octenidol & $\begin{array}{l}\text { Calcium hydroxide and } \\
\text { Chlorhexidine combination }\end{array}$ & 0.13 & 1.000 \\
\hline Octenidol & CHLORHEXIDINE & 0.47 & $0.045^{*}$ \\
\hline Octenidol & Control group & -0.80 & $<0.001^{*}$ \\
\hline $\begin{array}{l}\text { Calcium hydroxide and } \\
\text { Chlorhexidine combination }\end{array}$ & CHLORHEXIDINE & 0.33 & 0.476 \\
\hline $\begin{array}{l}\text { Calcium hydroxide and } \\
\text { Chlorhexidine combination }\end{array}$ & Control group & -0.93 & $<0.001^{*}$ \\
\hline CHLORHEXIDINE & Control group & -1.27 & $<0.001^{*}$ \\
\hline
\end{tabular}

Post-hoc bonferroni test* Significant difference

Table 7. CFU at day 3

\begin{tabular}{lccccc}
\hline & \multicolumn{3}{c}{ CFU at day 3 } & & \\
& Number & Mean & Std. Deviation & F-value & p-value \\
\hline Calcium hydroxide & 15 & 1.13 & 0.35 & 17.387 & $<0.001^{*}$ \\
Endoseptone & 15 & 0.67 & 0.62 & & \\
Octenidol & 15 & 0.53 & 0.52 & & \\
Calcium hydroxide and & 15 & 0.47 & 0.52 & \\
Chlorhexidine combination & & & & \\
CHLORHEXIDINE & 15 & 0.00 & 0.00 & \\
Control group & 15 & 1.40 & 0.51 & \\
\end{tabular}

One-way ANOVA test* Significant difference

kinds of bacteria ${ }^{18}$. Chlorohexidine attributes its antimicrobial activity through its cationic nature which easily pierces through the negatively charged bacterial membranes and leads to leaking of intracellular contents of the bacteria. More important about it is that it is effective against the bacteria resistant ${ }^{19}$.

In the present study manual Chlorhexidine was found to have the maximum antimicrobial efficacy followed by combination of calcium hydroxide and Chlorhexidine (1:1). Calcium hydroxide was found to be least effective showing minimum zones of inhibition at 24 hours and 72 hours and maximum colony forming units/ $\mathrm{ml}$ at day 1 . The results of the study were quite compatible to the studies done earlier. Many studies have been carried out to evaluate the antibacterial efficacy of intracanal medicaments being used ${ }^{20-22}$. According to a study carried out by Evans MD, Baumgartner JC et $\mathrm{al}^{23}$ in 2003 to evaluate the antibacterial efficacy of an intracanal medication composed of calcium hydroxide with 
$2 \%$ Chlorhexidine, the calcium hydroxide paste with $2 \%$ Chlorhexidine was found to be more effective at killing Enterococcus faecalis in the dentinal tubules than calcium hydroxide with water. While Masoud SAATCH, Ali SHOKRANEH, Hooman et al $(2014)^{24}$ in their study found out that that mixing $\mathrm{CH}$ with CHLORHEXIDINE does not improve its ex vivo antibacterial property as an intracanal medicament against Enterococcus faecalis.

Calcium hydroxide is used throughout the world since Hermann introduced it to dentistry in $1920^{25}$. This highly alkaline substance with $\mathrm{pH}$ of 12.5 approximately has antibacterial properties and has the ability to induce repair and stimulate hard tissue formation ${ }^{26}$. The antibacterial effect of calcium hydroxide results from the release of hydroxyl ions when it comes into contact with aqueous fluid ${ }^{27}$ and its main action is attributed to the effect of these ions on vital tissues ${ }^{28}$. However here in our study the calcium hydroxide alone is not sufficiently effective against bacteria. Though calcium hydroxide has

Table 8. Mean difference of CFU between various medicaments

\begin{tabular}{llcc}
\hline & \multicolumn{1}{c}{ CFU at day 3} & \\
& & Mean Difference & p-value \\
\hline Calcium hydroxide & Endoseptone & 0.47 & 0.109 \\
Calcium hydroxide & Octenidol & 0.60 & $0.010^{*}$ \\
Calcium hydroxide & Calcium hydroxide and & 0.67 & $0.003^{*}$ \\
& Chlorhexidine combination & & \\
Calcium hydroxide & CHLORHEXIDINE & 1.13 & $<0.001^{*}$ \\
Calcium hydroxide & Control group & -0.27 & 1.000 \\
Endoseptone & Octenidol & 0.13 & 1.000 \\
Endoseptone & Calcium hydroxide and & 0.20 & 1.000 \\
& Chlorhexidine combination & & \\
Endoseptone & CHLORHEXIDINE & 0.67 & $0.003^{*}$ \\
Endoseptone & Control group & -0.73 & $0.001^{*}$ \\
Octenidol & Calcium hydroxide and & 0.07 & 1.000 \\
Octenidol & Chlorhexidine combination & & \\
Octenidol & CHLORHEXIDINE & 0.53 & $0.035^{*}$ \\
Calcium hydroxide and & Control group & -0.87 & $0.001^{*}$ \\
Chlorhexidine combination & CHLORHEXIDINE & 0.47 & 0.109 \\
Calcium hydroxide and & Control group & & $<0.001^{*}$ \\
Chlorhexidine combination & & -0.93 & $<0.001^{*}$ \\
CHLORHEXIDINE & Control group & -1.40 & \\
\hline
\end{tabular}

Post-hoc bonferroni test* Significant difference

Table 9. CFU at day 5

\begin{tabular}{lccccc}
\hline & Number & $\begin{array}{c}\text { CFU at day 5 } \\
\text { Mean }\end{array}$ & Std. Deviation & F-value & p-value \\
\hline Calcium hydroxide & 15 & 1.20 & 0.41 & 17.093 & $<0.001^{*}$ \\
Endoseptone & 15 & 0.87 & 0.64 & & \\
Octenidol & 15 & 0.73 & 0.59 & \\
Calcium hydroxide and & 15 & 0.60 & 0.51 & \\
Chlorhexidine combination & 15 & 0.00 & 0.00 & \\
CHLORHEXIDINE & 15 & 1.53 & 0.52 & \\
Control group & & & & \\
\hline One-way ANOVA test* Significant difference & & & & \\
& & & & & \\
\hline Journal of Pure and Applied Microbiology & & &
\end{tabular}


a wide range of antimicrobial effects against common endodontic pathogens, but it is well reported to be less effective against specific species such as Enterococcus faecalis or Candida albicans. Numerous studies have also indicated that it exhibits a broad spectrum of antimicrobial activity against a variety of gram-positive and gram-negative bacteria (Bailey et al 1984, Sedlock and Bailey 1985$)^{29}$ and that this compound is also

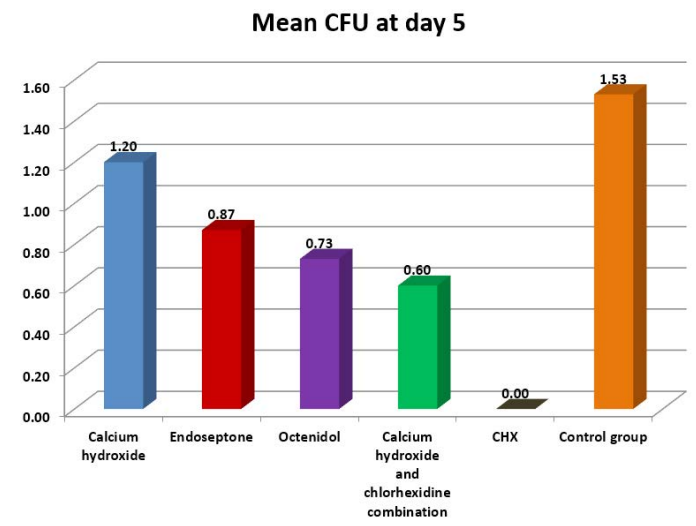

Fig. 5. Showing CFU at day 5 of various medicaments effective against plaque-producing organisms such as Actinomyces viscosus, Actinomyces naes/undii, Streptococcus mutans and Streptococcus sanguis ${ }^{30}$. OCTENIDOL aquais composed of PEG40 hydrogenated castor oil, glycerin, sodium gluconate, aroma, aspartame, octenidine dihydrochloride, citric acid.

Due to its specific capability to adhere and form complexes with chemical cell components and whole cells along with its high antimicrobial efficacy, octenidine dihydrochloride (octenidine) may be considered as a unique antimicrobial agent exerting its activity through non-cytotoxic complexes on the site of action. Octenidine shows properties of positively charged (cation active) chemical compounds. Octenidine has been well reported to show greater effectiveness as an inhibitor to plaque-forming enzymes of Streptococcus mutans than Chlorhexidine or alexidine (Bailey et al 1984) ${ }^{31}$. However it's status as inhibitor to Enterococcus faecalis, is conflicting and thereby has been, assessed for its activity against the bacteria. In our study the compound Octenidine has given relatively low efficacious

Table 10. Difference of CFU at day 5 between various medicaments

\begin{tabular}{llcc}
\hline & \multicolumn{1}{c}{ CFU at day 5 } & \\
& & Mean Difference & p-value \\
\hline Calcium hydroxide & Endoseptone & 0.33 & 1.000 \\
Calcium hydroxide & Octenidol & 0.47 & 0.168 \\
Calcium hydroxide & Calcium hydroxide and & 0.60 & $0.019^{*}$ \\
& Chlorhexidine combination & & \\
Calcium hydroxide & CHLORHEXIDINE & 1.20 & $<0.001^{*}$ \\
Calcium hydroxide & Control group & -0.33 & 1.000 \\
Endoseptone & Octenidol & 0.13 & 1.000 \\
Endoseptone & Calcium hydroxide and & 0.27 & 1.000 \\
Endoseptone & Chlorhexidine combination & & \\
Endoseptone & CHLORHEXIDINE & 0.87 & $<0.001^{*}$ \\
Octenidol & Control group & -0.67 & $0.006^{*}$ \\
& Calcium hydroxide and & 0.13 & 1.000 \\
Octenidol & Chlorhexidine combination & & \\
Octenidol & CHLORHEXIDINE & 0.73 & $0.002^{*}$ \\
Calcium hydroxide and & Control group & -0.80 & $<0.001^{*}$ \\
Chlorhexidine combination & CHLORHEXIDINE & 0.60 & $0.019^{*}$ \\
Calcium hydroxide and & Control group & & \\
Chlorhexidine combination & Control group & -0.93 & $<0.001^{*}$ \\
CHLORHEXIDINE & & -1.53 & $<0.001^{*}$ \\
\hline Post-hoc bonfertonitest & & &
\end{tabular}

Post-hoc bonferroni test* Significant difference 
results as an antimicrobial agent as compared to chlorohexidine.

ENDOSEPTONE consists of $p$ Chlorophenol $30 \%$, Dexamethasone Acetate and Thymol. Endoseptone is a solution which offers a triple action of being bactericidal, sedative and anti inflammatory. It also reduces the risk of allergic reactions, have a higher antibacterial, antiseptic and disinfectant potential compared to other disinfectants or pheno ${ }^{32}$. But in comparison to chlorohexidine its antimicrobial activity was found to be very poor.

Chlorhexidine has a reasonably wide range of activity against aerobic and anaerobic organisms. This might be responsible for its high antimicrobial activity against Enterococcus faecalis .At low concentrations of Chlorhexidine, small molecular weight substances will leak out, resulting in a bacteriostatic effect. At higher concentrations, Chlorhexidine has a bactericidal effect due to precipitation and coagulation of the cytoplasm probably caused by protein cross linking. One of the mechanisms that explain its efficacy is based on the interaction between the positive charge of the molecule and negatively charged phosphate groups on the bacterial cell wall, which allows the Chlorhexidine molecule to penetrate into the bacteria with toxic effects.

\section{CONCLUSION}

In the present study manual Chlorhexidine was found to have the maximum antimicrobial efficacy followed by combination of calcium hydroxide and Chlorhexidine (1:1). Calcium hydroxide was found to be least effective showing minimum zones of inhibition at 24 hours and 72 hours and maximum colony forming units $/ \mathrm{ml}$ at day 1 . Within the limitations of this study it may be concluded that Chlorhexidine can be used as an efficient intracanal medicament. However, present study also supports the use of Octenidol as a promising intracanal medicament.

\section{ACKNOWLEDGEMENT}

Authors thankfully acknowledge the support from Santosh Group of Institutions for providing all necessary support for conducting research.

\section{CONFLICT OF INTEREST}

The authors declare that there is no conflict of interest.

\section{DATA AVAILABILITY}

All datasets generated or analyzed during this study are included in the manuscript.

\section{ETHICS STATEMENT}

This article does not contain any studies with human participants or animals performed by any of the authors.

\section{REFERENCES}

1. Lin Y, Mickel A, Chogle S. Effectiveness of selected materials against Enterococcus faecalis: Part 3. J Endod 2003; 29565-6.

2. McHugh $\mathrm{CP}$, Zhang $\mathrm{P}$, Michalek S, Eleazer PD. $\mathrm{pH}$ required to kill Enterococcus faecalis in vivo. J Endod 2004; 30: 218-9. https://doi.org/10.1097/00004770200404000-00008.

3. Maryam Zare Jahromi et al; Propolis: A New Alternative for Root Canal Disinfection; Iranian Endodontic Journal 2012; 7(3): 127-133

4. L Lakshmi Narayanan and C Vaishnavi ;Endodontic microbiology; conserve dent 2010; 13(4): 233-239. https://doi.org/10.4103/0972-0707.73386.

5. Mickel AK, Ngyan Th,Chogle S. Antimicrobial activity of endo sealers on Enterococcus faecalis. JOE 2003; 29(4):257-58. https://doi.org/10.1097/00004770200304000-00006.

6. Sonia Bhonchal Bhardwaj; Role of Enterococci faecalis in failure of Endodontic treatment Bhardwaj Int.J.Curr. Microbiol.App.Sci, 2013: 2(8): 272-277.

7. Gonzalo H Oporto V, Cynthia Rodraguez-Niklitschek; Clinical implications of Enterococcus faecalis microbial contamination in root canals of devitalized teeth: Literature review, 19(3): e177-e182. https://doi. org/10.1016/j.rodmex.2016.02.024.

8. Atila-Pektas B, Yurdakul P, Gulmez D, Gorduysus O. Antimicrobial effects of root canal medicaments against Enterococcus faecalis and Streptococcus mutans. Int Endod J. 2013; 46(5):413-8. https://doi. org/10.1111/iej.12004.

9. Jeonsonne M, White RR. A comparison of $2 \%$ Chlorhexidine and $5.25 \% \mathrm{Naocl}$ as an antimicrobial endodontic irrigant. J Endod-1994; 20:276-78. https:// doi.org/10.1016/S0099-2399(06)80815-0.

10. Mohammadi $Z^{1}$, Dummer PM. Properties and applications of calcium hydroxide in endodontics and dental traumatology. Int Endod J. 2011;44(8):697-730. https://doi.org/10.1111/j.1365-2591.2011.01886.x.

11. P carrotte; calcium hydroxide, root resorption,endo perio lesion: British Dental journal, 197735-43(2004).

12. Masoud SAATCHI, Ali SHOKRANEH, Hooman NAVAEI, Mohammad Reza MARACY, and Hasan SHOJAEI. Antibacterial effect of calcium hydroxide combined with Chlorhexidine on Enterococcus faecalis: a systematic review and meta-analysis.J 
Appl oral sci 2014 Sep-Oct; 22(5): 356-365. The role of Octenidol $^{\circ}$, Glandomed ${ }^{\circ}$ and chlorhexidine mouthwash in the prevention of mucositis and in the reduction of the oropharyngeal flora: a doubleblind randomized controlled trial. https://doi. org/10.1590/1678-775720140032.

13. Masoud SAATCHI, Ali SHOKRANEH, Hooman NAVAEI, Mohammad Reza MARACY, and Hasan SHOJAEI. Antibacterial effect of calcium hydroxide combined with Chlorhexidine on Enterococcus faecalis: a systematic review and meta-analysis.J Appl oral sci 2014 Sep-Oct; 22(5): 356-365. The role of Octenidol $^{\circ}$, Glandomed ${ }^{\circ}$ and chlorhexidine mouthwash in the prevention of mucositis and in the reduction of the oropharyngeal flora: a doubleblind randomized controlled trial. https://doi. org/10.1590/1678-775720140032.

14. Nico T. Mutters, Thomas R. Neubert, Rudolf Nieth, and Reinier Mutters*. The role of Octenidol, Glandomed and Chlorhexidine mouthwash in the prevention of mucositis and in the reduction of oropharyngeal flora: A double blind randomized controlled trial. GMS Hygeine Infection control 2015;10:05The role of Octenidol ${ }^{\circ}$, Glandomed ${ }^{\circ}$ and chlorhexidine mouthwash in the prevention of mucositis and in the reduction of the oropharyngeal flora: a double-blind randomized controlled trial.

15. HS Bhargav et al Measurement of zone of inhibition of an antibiotic ieeexplore.ieee.org

16. S Sieuwerts et al A simple and fast method for determining colony forming units Letter in applied micrfobiology 2008; 47: 275-278. https://doi. org/10.1111/j.1472-765X.2008.02417.x.

17. Richard Peto Current misconception 3 : that subgroupspecific trial mortality results often provide a good basis of individualizing patient care $\mathrm{Br}$ j Cancer 2011; 104(7): 1057-1058. https://doi.org/10.1038/ bjc.2011.79

18. Farhad A, Mohammadi Z. Calcium hydroxide: A review. Int.Dent J. 2005; 55: 293-301. https://doi. org/10.1111/j.1875-595X.2005.tb00326.x

19. Ferraz $\mathrm{CC}^{1}$, Gomes BP, Zaia AA, Teixeira FB, Souza-Filho FJ.In vitro assessment of the antimicrobial action and the mechanical ability of Chlorhexidine gel as an endodontic irrigant.J Endod 2001 Jul;27(7):452-5. https://doi.org/10.1097/00004770-200107000-00004

20. McHugh, C.P., Zhang, P., Michalek, S., Eleazer, P.D. $\mathrm{pH}$ required to kill Enterococcus faecalis in vitro. J Endod. ;2004;30:218-219. https://doi. org/10.1097/00004770-200404000-00008

21. Charles H. Stuart, Scott A. Schwartz, Thomas J. Beeson, Christopher B. Owatz, Enterococcus faecalis: Its Role in Root Canal Treatment Failure and Current Concepts in Retreatment.JOE: Feb 2006 Volume 32, Issue 2, Pages93-98. https://doi.org/10.1016/j. joen.2005.10.049.
22. Koch $\mathrm{S}^{1}$, Hufnagel $\mathrm{M}$, Theilacker $\mathrm{C}$, Huebner J. .Enterococcal infections: host response, therapeutic, and prophylactic possibilities. 2004;2 2(7):822-30. https://doi.org/10.1016/j.vaccine.2003.11.027

23. Evans, Baumgartner JC, Khemaleelakul SU, Xia T. Efficacy of calcium hydroxide: Chlorhexidine paste as an intracanal medication in bovine dentin. $J$ Endod. 2003; 29(5):338-9. https://doi.org/10.1097/00004770200305000-00005

24. Masoud SAATCHI, Ali SHOKRANEH, Hooman NAVAEI, Mohammad Reza MARACY,Hasan SHOJAEI Antibacterial effect of calcium hydroxide combined with chlorhexidine on Enterococcus faecalis: a systematic review and meta-analysis J Appl Oral Sci. 2014; 22(5): 356-365. https://doi.org/10.1097/00004770200305000-00005

25. Dammaschke TThe history of direct pulp capping $J$ Hist Dent. 2008; 56(1):9-23.

26. Grossman, Dohyun Kim and Euiseong Kim Antimicrobial effect of calcium hydroxide as an intracanal medicament in root canal treatment: a literature review - Part I. In vitro studies. Restor Dent Endod 2014; (4): 241-252. https://doi.org/10.5395/ rde.2014.39.4.241

27. Farhad A, Mohammadi Z. Calcium hydroxide: A review. Int.Dent J. 2005; 55: 293-301. https://doi. org/10.1111/j.1875-595X.2005.tb00326.x

28. Delany GM, Patterson SS, Miller CH, Newton CW. The effect of Chlorhexidine gluconate irrigation on the root canal flora of freshly extracted necrotic teeth. Oral Surg Oral Med Oral Pathol 1982; 53(5):518-23. https://doi. org/10.1016/0030-4220(82)90469-8

29. Slee AM, O'Connor JR. In vitro antiplaque activity of octenidine dihydrochloride (WIN 41464-2) against preformed plaques of selected oral plaque-forming microorganisms. Antimicrob Agents Chemother. 1983; 23(3):379-384. https://doi.org/10.1128/AAC.23.3.379

30. Bailey DM, DeGrazia CG, Hoff SJ, Schulenberg PL, O'Connor JR, Paris DA, Slee AM. Bispyridinamines: a new class of topical antimicrobial agents as inhibitors of dental plaque. J Med Chem. 1984; 27(11):14571464. https://doi.org/10.1021/jm00377a014

31. Evans MD(1), Baumgartner JC, Khemaleelakul SU, Xia T. Efficacy of calcium hydroxide: Chlorhexidine paste as an intracanal medication in bovine dentin. $J$ Endod. 2003; 29(5):338-9. https://doi.org/10.1097/00004770200305000-00005

32. Da Silva GN, De Camargo EA, Salvadori DM, Ribeiro DA. Genetic damage in human peripheral lymphocytes exposed to antimicrobial endodontic agents. Oral Surg Oral Med Oral Pathol Oral Radiol Endod. 2007; 104:e58-61. https://doi.org/10.1016/j. tripleo.2007.02.009 